\title{
Commitment with or without a stick of paid work: Comparison of paid and unpaid workers in a nonprofit organization
}

\author{
Mark van Vuuren, Menno D. T. de Jong, and Erwin R. Seydel \\ Institute for Behavioral Research, University of Twente, The Netherlands
}

\begin{abstract}
The aim of this study is to investigate whether nonpaid volunteers have other reasons to be a member of an organization than paid workers. Volunteers are assumed to be hard to manage, because there is no "stick of a paid contract" to keep them in line. Therefore, we studied different dimensions (i.e., affective, normative, and continuance) of organizational commitment of volunteers and paid workers in a nonprofit organization. Further, we assessed whether the predictive power of the congruence between organizational and individual values for commitment differs between paid and unpaid workers. As expected, volunteers showed a significantly higher level of affective commitment to the organization, and lower levels of continuance commitment. Surprisingly, volunteers also showed a higher level of normative commitment than paid workers. Theoretical and practical implications of the findings are discussed.
\end{abstract}

Keywords: Volunteers; Non-profit; Organizational commitment; Personorganization fit; Life-span.

There are reasons abound for people to work in a certain organization beside financial considerations, as volunteers prove every single day. The majority of the organizational research on voluntarism has been dedicated to the study of volunteer organizations. Since volunteer organizations completely depend on the commitment of volunteers, these organizations and the well-being of these volunteers receive most research attention. In practice, however, voluntarism also plays an important role in hybrid organizations, where both paid and unpaid members work together towards achieving the organization's goals. Research attention for unpaid volunteers who work in organizations where most employees are paid workers with a

Correspondence should be addressed to Mark van Vuuren, PO Box 217, 7500 AE Enschede, The Netherlands. E-mail: h.a.vanvuuren@utwente.nl

(C) 2007 Psychology Press, an imprint of the Taylor \& Francis Group, an Informa business http://www.psypress.com/ejwop

DOI: $10.1080 / 13594320701693175$ 
contract is therefore justified. Moreover, such hybrid organizations offer the unique possibility to compare the job-related attitudes of paid and unpaid workers, which will contribute to our understanding of the nature of voluntarism in organizations. In this article, we will report on a study in which we compared job-related attitudes of paid and unpaid members working in the same organization.

A mixed employee force is a complex context to work in, for paid workers, volunteers, and management alike. Paid workers may see volunteers as a threat to their own position in the organization. When volunteers bring in valuable experience and credentials, paid staff members may feel threatened (McCurley \& Lynch, 1996), and in reaction stress the boundaries between professionalism and voluntarism. Such a competitive atmosphere between paid and unpaid workers may demoralize volunteers. When they realize that their contribution to the organization is not as welcome as they may have hoped for and their lofty dedication to the organization is not respected, they may feel less motivated to exert themselves for the organization.

Managers may have their own reservations to employ volunteers. Volunteers are said to be hard to manage, because there is no "stick of a paid contract" to keep them in line (Cookman, Haynes, \& Streatfield, 2000, p. 20). It is also assumed that volunteers will easily withdraw from the organization, due to the lack of financial consequences of such a decision. Managers may think that only altruistic dispositions of volunteers bind them to the organization. Despite the unquestionable benefits of voluntary workers in an organization, managers may be reluctant to place tasks in the hands of volunteers. More precisely, it may be the perceived lack of interdependence that comes with nonpaid work that restrains organizations from embracing the opportunities offered by volunteers.

These managerial reservations regarding voluntarism can be reframed in terms of organizational commitment, which refers to a force that binds an individual to activities that are relevant to one or more goals (Meyer \& Herscovitch, 2001). Organizational commitment has been found to correlate with enhanced work efforts, better performance, and reduced absenteeism and turnover (see Meyer, Stanley, Herscovitch, \& Topolnytsky, 2002, for a review). Although correlations cannot prove causation by themselves, the idea that commitment often goes hand in hand with these favourable behaviours has attracted attention of both practitioners and scholars alike. Organizational commitment has been shown to incorporate three distinct dimensions: affective, normative, and continuance commitment (Meyer \& Allen, 1997). In essence, the aforementioned managerial hesitations when considering the added value of volunteers refer to each of these dimensions. In this study, we will therefore compare the three dimensions of organizational commitment of paid and unpaid workers in 
one organization, because knowledge of these attitudes may lead to a better understanding and a decrease of tension between the two groups in an organization.

Affective commitment reflects a person's emotional attachment with the organization. Affectively committed employees will be more likely to show organizational citizenship behaviours, be absent less, and have fewer turnover intentions (e.g., Eby, Freeman, Rush, \& Lance, 1999; Farrell \& Stamm, 1988; Feather \& Rauter, 2004; Tett \& Meyer, 1993). Affective commitment finds its origin in recognition of the values of the organization (Meyer \& Herscovitch, 2001) and refers to intrinsic motivation of volunteers and their feelings about the organization (Meyer, Becker, \& Vandenberghe, 2004). It seems reasonable to assume that volunteers who enter and stay in an organization will have firm affective commitment to their organization, as their desire for contributing stems from a careful process of "sorting out priorities, and matching of personal capabilities and interests" (Benson et al., 1980, p. 89).

This "matching" in reference to affective organizational commitment is similar to the concept of person-organization fit (Cable \& DeRue, 2002; Kristof, 1996), which has been studied extensively in relation to affective commitment (see Kristof-Brown, Zimmerman, \& Johnson, 2005, for a review). Catano, Pond, and Kelloway (2001) state that "[i]ndividuals join voluntary organizations because of the compatibility of their beliefs with the values of the organization" (p. 257), hence person-organization fit. People who also need other rewards of work (like financial compensation) will presumably not base their activities and commitment solely on these valuebased considerations and affections. In contrast to paid workers, we propose that volunteers will have both higher affective commitment and personorganization fit. Moreover, affective commitment will be more strongly related to perceived person-organization fit with volunteers than with paid staff. As such we hypothesize that:

Hypothesis 1. Volunteers will show higher affective commitment to the organization than paid workers.

Hypothesis 2a. Volunteers will show higher person-organization fit than paid workers.

Hypothesis 2b. Affective commitment of volunteers will be stronger related to person-organization fit than paid workers' affective commitment.

The normative commitment dimension of the Meyer and Allen (1997) model indicates a sense of obligation and loyalty towards the organizationfor example, a "psychological contract", which flows from a belief in mutual obligations (Dabos \& Rousseau, 2004). This reciprocal nature of a working 
relationship may be more central to paid workers, as their relationship with the organization is more contractual than for volunteers.

Meyer and Allen (1991) define continuance commitment as "an awareness of the costs associated with leaving the organization" (p. 67). Quitting an organization can lead to the loss of important (im)material benefits and incentives like income, prestige, or side-bets (Powell \& Meyer, 2004). For volunteers, these "golden handcuffs" will presumably be less prominent, as there is no "stick of paid work" involved. The perceived lack of alternatives is presumably also smaller for volunteers than for paid members of the organization (cf. Laczo \& Hanisch, 1999).

Further, it has been suggested that both normative and continuance commitment are related to employees' perceptions of the transactional contract they have with their organization, in contrast to mere socioemotional or "relational" considerations of such contracts (Meyer, Allen, \& Topolnytsky, 1998; Rousseau \& McLean Parks, 1993; van Vuuren, Veldkamp, de Jong, \& Seydel, in press). A transactional contract is based on employees' perceptions of "specific, short-term and monetizable obligations" (Meyer et al., 1998, p. 85) from an organization to their members. When normative and continuance commitment are indeed linked to a transactional contract, the evaluation of monetizable obligations may be more important for paid workers than for volunteers. We have not found any empirical evidence indicating a direction for this relationship and therefore this question remains rather exploratory, but based on the aforementioned considerations of the nature of these commitments, we suggest the following pattern:

Hypothesis 3. Volunteers will show lower normative commitment to the organization than paid workers.

Hypothesis 4. Volunteers will show lower levels of continuance commitment to the organization than paid workers.

\section{THE PRESENT STUDY}

We investigated a group of paid and unpaid workers in a study on organizational commitment in a nonprofit organization. The organization's mission is to provide services for blind and weak-sighted people in areas like education, physical aid, and ergonomic adaptation. For everyone, from children to elderly people, the organization exerts itself so that their clients can live, study, and work as independently as possible. The organization also strives for the diffusion of knowledge and understanding in society about the life of visually impaired. Most of the organization's members $\left(N_{1}=1351\right)$ are paid workers (e.g., teachers, caregivers), but there is also a 
group of nonpaid volunteers $\left(N_{2}=257\right)$ who provide specific help like personal care, driving buses, and taking clients out for a walk.

Questionnaires and prepaid postage envelopes were sent to the home addresses of all 1608 individual organization members, i.e., including the volunteers. 655 questionnaires were returned $\left(N_{1}=597\right.$, a response rate of $44 \% ; N_{2}=57$ a response rate of $22 \%$ ). We propose two reasons for the difference in response rate between the two groups. First, the respondents were addressed as "members" in the questionnaire, and some volunteers believed that this did not apply to them. Management believed that the label "member" would include both paid and unpaid workers, but some volunteers responded within a few days that the questionnaire was not applicable to their specific situation. Although the CEO tried to correct this misperception in a letter to all volunteers, this initial confusion may have had negative effects on their response rate. Second, the amount of time spent by volunteers in the organization varied, and some volunteers may have perceived their contribution to the organization too small to participate in the survey. For example, one volunteer wrote that because her activities were limited to 1 hour per week, in which she took one of the clients for a walk, the questions were hard for her to answer.

Seventy per cent of respondents were women; mean tenure was 8 years. Mean age was 46, and elder people were significantly overrepresented compared to the entire organization. Comparison of the characteristics of paid and unpaid respondents showed that the group of volunteers included more females, and that the volunteer group was relatively older than the group of paid workers. This difference reflects the actual state in the organization, as voluntary work is relatively often done by older women. Although this is an indication that the results will reflect the real mindsets of both volunteers and paid workers as they are present in organizations, in a secondary analysis we will test for confounding effects of both age and gender.

We used Meyer and Allen's (1991) scales to measure affective organizational commitment (six items, e.g., "I feel a strong sense of belonging to my organization", Cronbach's alpha $=.82$ ), normative organizational commitment (five items, e.g., "Even if it were to my advantage, I do not feel it would be right to leave my organization now", Cronbach's alpha $=.70$ ), and continuance organizational commitment (five items, e.g., "I believe that I have too few options to consider leaving this organization", Cronbach's alpha $=.75)$. We measured person-organization fit with the three-item scale used by Cable and DeRue (2002; e.g., "My organization's values and culture provide a good fit with the things I value in life", Cronbach's alpha $=.85$ ).

For all measures we used a 7-point Likert scale ranging from "strongly disagree" to "strongly agree". All measures were in Dutch. We used the 
standardized Dutch translation of Meyer et al.'s (1991) organizational commitment scale (de Gilder, van den Heuvel, \& Ellemers, 1997). The person-organization fit scale (Cable \& DeRue, 2002) was translated into Dutch. The scale was translated independently by two of the researchers. A comparison of the translation led to a renewed version. A back-translation of this scale by someone who was not familiar with the original scale assured that the essence of the concept was retained in the translation.

\section{RESULTS}

To test the hypotheses about the dimensions of commitment, we conducted a $t$-test (see Tables 1 and 2). As each Levene's test of homogeneity showed nonsignificant results, we calculated Cohen's $d$ for an indication of the effect size.

\section{TABLE 1}

Means, standard deviations, and correlations for affective, normative, and continuance commitment and person-organization fit for both paid and nonpaid workers

\begin{tabular}{lcccccr}
\hline & Mean & $S D$ & 1 & 2 & 3 & 4 \\
\hline Volunteers $^{1}$ & & & & & & \\
1. Affective commitment & 5.10 & 1.00 & - & & & \\
2. Normative commitment & 4.22 & 1.07 & .51 & - & & \\
3. Continuance commitment & 3.30 & 1.10 & .37 & .43 & - & \\
4. Person-organization fit & 5.47 & 0.94 & .78 & .44 & .17 & - \\
Paid workers & & & & & & \\
1. Affective commitment & 4.52 & 1.03 & - & & & \\
2. Normative commitment & 3.33 & 1.01 & .49 & - & & \\
3. Continuance commitment & 3.40 & 1.29 & .24 & .28 & - & \\
4. Person-organization fit & 5.01 & 1.05 & .50 & 23 & .01 & - \\
\hline
\end{tabular}

${ }^{1}$ All correlations significant at the .01 level (2-tailed). $N=57$.

${ }^{2}$ All correlations significant at the .01 level (2-tailed). $N=597$.

TABLE 2

$T$-test for the means of affective, normative, and continuance commitment, and personorganization fit

\begin{tabular}{lcccr}
\hline & t-test & $d f$ & $p$ & Cohen's d \\
\hline Affective commitment & 3.66 & 628 & .000 & 0.59 \\
Normative commitment & 5.57 & 626 & .000 & 0.89 \\
Continuance commitment & 0.53 & 623 & $n s$ & -0.08 \\
Person-organization fit & 2.83 & 625 & .005 & 0.48 \\
\hline
\end{tabular}


The results show that volunteers have higher affective commitment, thereby confirming Hypothesis 1 (Cohen's $d=0.59$, an indication of a medium effect). Furthermore, Hypothesis 2a was confirmed: The volunteers showed higher levels of person-organization fit (Cohen's $d=0.48$, an indication of a medium effect). We also assumed that person-organization fit would better predict affective commitment for volunteers than for paid workers (Hypothesis 2b). Therefore, we conducted a hierarchical regression analysis to test for an interaction effect of worker status (paid/ unpaid) and person-organization fit, controlling for the main effects of both variables (see Figure 1).

The interaction was significant, $\beta=.658, F(1,650)=6.93, p<.01$, thereby confirming Hypothesis $2 \mathrm{~b}$. The correlations already hinted to differences between volunteers and paid workers regarding the link between fit perceptions and affective commitment (Table 1), and this difference was confirmed by the regression analysis.

For normative commitment, however, the results were contrary to our expectations (Hypothesis 3). Volunteers reported having a much higher level of normative commitment to the organization than paid workers (Cohen's $d=0.89$, an indication of a large effect). Furthermore, the hypothesis regarding continuance commitment (Hypothesis 4), i.e., that volunteers would have lower continuance commitment than paid workers, was not confirmed in this study. No significant difference was found between volunteers and paid workers in their attitudes towards the perceived lack of alternatives and the loss of investments when leaving the organization.

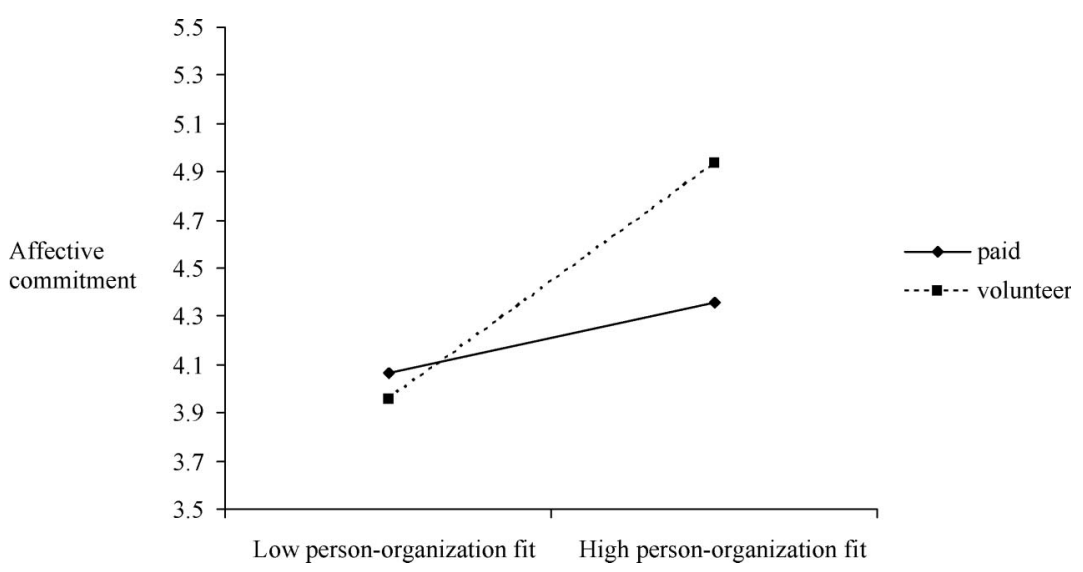

Figure 1. The moderating effect of group (paid/volunteer) on the relationship between personorganization fit and affective commitment. 
These results lay bare the commitment patterns of paid and unpaid workers, but disregard the fact that these groups differed concerning age and gender. Whether the findings can be attributed to the nature of voluntarism, a second analysis was conducted controlling for age and gender as potential confounders in a mixed model design. It turned out that gender was not a confounder, but age had a positive effect for affective, $B=0.11, S E=0.04$, $p<.05$, normative, $B=0.18, S E=0.04, p<.001$, and continuance commitment, $B=0.26, S E=0.05, p<.001$, and person-organization fit, $B=0.10$, $S E=0.05, p<.05$.

Our second analysis indeed changed the results for some of the hypotheses. For affective and normative organizational commitment, the results stayed the same: Volunteers report stronger affective, $B=0.38$, $S E=0.16, p<.001$, and normative, $B=0.70, S E=0.16, p<.001$, commitment than paid workers. For the other variables, however, the initial nonsignificant effect turns out to be confounded by age: After controlling volunteers appear to have lower continuance commitment than paid workers, as hypothesized, $B=-0.46, S E=0.20, p<.05$. For personorganization fit, the differences between paid and unpaid workers turned out to be nonsignificant after controlling for confounders, $B=0.23, S E=0.18$, $p=.19$.

In all, age turned out to be a confounder for the commitment dimensions and person-organization fit, thereby influencing the results (see Table 3 for an overview). We will reflect on these results in the Discussion.

\section{DISCUSSION}

The purpose of this study was to gain insight in the commitment pattern of volunteers compared to their paid co-workers. Regardless of their age, volunteers report higher levels of affective commitment (as previous scholars had already proposed; see, for example, Catano et al., 2001; Clary et al., 1998; Wilson \& Pimm, 1996). Furthermore, this study showed that the importance of perceived person-organization fit for affective commitment is

TABLE 3

Comparison of support for hypotheses before and after confounder control (age and gender)

\begin{tabular}{llll}
\hline & Hypothesis & $\begin{array}{l}\text { Support before } \\
\text { confounder control? }\end{array}$ & $\begin{array}{l}\text { Support after } \\
\text { confounder control? }\end{array}$ \\
\hline Affective commitment & Paid < unpaid & Supported & Supported \\
Normative commitment & Paid > unpaid & Opposite & Opposite \\
Continuance commitment & Paid > unpaid & Not supported & Supported \\
Person-organization fit & Paid < unpaid & Supported & Not supported \\
\hline
\end{tabular}


even greater for volunteers than for paid workers, for whom this also is an important feature (cf. Kristof, 1996) - although this effect has to be attributed to the age of the respondents. The results of the proposed hypotheses about both normative and continuance commitment were surprising. Volunteers did show higher levels of normative commitment than paid workers, and there was no difference in continuance commitment between the two groups.

Contrary to our expectations, the volunteers had higher levels of normative commitment than the paid workers, even when controlling for differences in age and gender between the two groups. The question arises how to explain the surprisingly strong normative commitment of the volunteers. We propose that an explanation lies in the characteristics of the volunteers in this organization. Research on volunteering related to the human life span (Erickson, 1994) shows that older people are motivated to volunteer because of their wish to fulfil an obligation or commitment to society; this in contrast to younger volunteers, who are primarily in search of satisfying interpersonal relationships (Omoto, Snyder, \& Martino, 2000). The fact that volunteers in this organization are relatively old implies that the tasks that are open for volunteers appeal to the generativity of the elder segment of societies' volunteer population. Our initial hypothesis was that paid workers would be stronger normatively committed based on the principle of reciprocity (Dabos \& Rousseau, 2004). But incorporating Omoto et al.'s (2000) life span argumentation, normative commitment may also enhance through the generativity drives of older members of society. To our knowledge, this is a new aspect of normative commitment in desperate need of future research.

As the age of the respondents confounded the relationship between the two groups and their continuance commitment, one has to be careful interpreting the results. Our initial analysis showed that volunteers had the same level of continuance commitment as paid workers, but subsequent analysis revealed that this must be attributed to age differences. Based on these results, it must concluded that, in general, volunteers indeed will show lower levels of continuance commitment than paid workers. Paid workers who consider leaving their organization will - in contrast to volunteershave to cope with (financial) insecurity that comes with such a decision. As continuance commitment comes with age, organizations attracting older volunteers, however, may experience their volunteers having a continuance commitment as strong as their paid workforce.

Note that findings based on cross-sectional data are to be handled with caution, especially when gathered in a single organization. Furthermore, volunteers with a marginal contribution to the organization may be underrepresented in our study, as they perceived questions about organizational commitment to be less relevant to their situation. More research, 
preferably in hybrid organizations with both paid and unpaid workers, may shed light on the generalizability of our findings.

From a managerial point of view, the results of this study offer several preliminary insights in the functioning of volunteers in organizations. First, person-organization fit, which has been shown to be an important antecedent of affective commitment in general, seems to be even more influential for volunteers than for paid workers. If organizations are able to communicate how their goals, values, and culture are congruent to the individual's beliefs, volunteers can indeed be very helpful and committed organizational members. Given the influence of age in this respect, this is especially true when volunteer-based organizations could emphasize their contribution to society's benefit, as this is most important for volunteers in later life (Omoto et al., 2000). This will be rewarding for both parties involved. Explicit communication of values thus compensates for the absence of an organization's pay and reward system for volunteers, as it reveals what kinds of behaviour are valued. Second, given that the volunteers' sense of commitment appears to be similar to or (in the case of affective and normative commitment) even stronger than the commitment of paid workers, it is crucial to fully acknowledge their membership of the organization. Management has to make sure that volunteers are not belittled and do not "perceive themselves as the 'poor bloody infantry' with the officers and other full-time staff creaming off the attractive, rewarding or exciting activities" (Wilson \& Pimm, 1996, p. 28). What is more, the apparent attachment of volunteers towards the organization makes the organization responsible for the much-needed support of the voluntary members of the organization.

As mentioned before (cf. Pearce, 1993), the fact that the volunteers' attitudes appear to be favourable in many respects does not necessarily imply the corresponding behavioural consequences. A study by Laczo and Hanisch (1999) suggests that commitment may have less impact on the intentions of volunteers to stay with their organization compared to paid workers. In general, however, a clear relationship is found between the three commitment dimensions and behaviour (Bentein, Vandenberg, Vandenberghe, \& Stinglhamber, 2005; Meyer et al., 2002). The results of this study show that not only can affective commitment be found with volunteers, but that especially normative commitment can emerge. As commitment of volunteers springs from several wells, their commitment may not be as fragile as is often assumed.

This study showed that the absence of "the stick of paid work" does not lead to the situation that volunteers leave their tasks very easily. As indicated by their commitment, there seems to be an interdependence, even though volunteers are not paid for their contribution. They may need the organization as much as the organization needs them. 


\section{REFERENCES}

Benson, P. L., Dehority, J., Garman, L., Hanson, E., Hochschwender, M., Lebold, C., et al. (1980). Intrapersonal correlates of nonspontaneous helping behavior. Journal of Social Psychology, 110, 89-95.

Bentein, K., Vandenberg, R., Vandenberghe, C., \& Stinglhamber, F. (2005). The role of change in the relationship between commitment and turnover: A latent growth modeling approach. Journal of Applied Psychology, 90, 468-482.

Cable, D. M., \& DeRue, D. S. (2002). The convergent and discriminant validity of subjective fit perceptions. Journal of Applied Psychology, 87, 875-884.

Catano, V. M., Pond, M., \& Kelloway, E. K. (2001). Exploring commitment and leadership in volunteer organizations. Leadership and Organization Development, 22, 256-263.

Clary, E., Snyder, M., Ridge, R., Copeland, J., Stukas, A., Haugen, J., \& Miene, P. (1998). Understanding and assessing the motivations of volunteers: A functional approach. Journal of Personality and Social Psychology, 74, 1516-1530.

Cookman, N., Haynes, D., \& Streatfield, D. (2000). The use of volunteers in public libraries. London: Library Association.

Dabos, G. E., \& Rousseau, D. M. (2004). Mutuality and reciprocity in the psychological contracts of employees and employers. Journal of Applied Psychology, 89, 52-72.

De Gilder, D., van den Heuvel, H., \& Ellemers, N. (1997). Het 3-componenten model van commitment [The three component model of commitment]. Gedrag en Organisatie, 10, $95-105$.

Eby, L. T., Freeman, D. M., Rush, M. C., \& Lance, C. E. (1999). The motivational bases of affective organizational commitment. Journal of Occupational and Organizational Psychology, 72, 463-483.

Erickson, E. (1994). Identity and the life cycle. New York: Norton.

Farrell, D., \& Stamm, C. L. (1988). Meta-analysis of the correlates of employee absence. Human Relations, 41, 211-227.

Feather, N. T., \& Rauter, K. A. (2004). Organizational citizenship behaviours in relation to job status, job insecurity, organizational commitment an identification, job satisfaction and work values. Journal of Organizational and Occupational Psychology, $77,81-94$.

Kristof, A. L. (1996). Person-organization fit: An integrative review of its conceptualizations, measurement, and implications. Personnel Psychology, 49, 1-49.

Kristof-Brown, A. L., Zimmerman, R. D., \& Johnson, E. C. (2005). Consequences of individual's fit at work: A meta-analysis of person-job, person-organization, person-group, and person-supervisor fit. Personnel Psychology, 58, 281-342.

Laczo, R. M., \& Hanisch, K. A. (1999). An examination of behavioral families of organizational withdrawal in volunteer workers and paid employees. Human Resource Management Review, 9, 453-477.

McCurley, S., \& Lynch, R. (1996). Volunteer management. Downers Grove, IL: Heritage Arts Publishing.

Meyer, J. P., \& Allen, N. J. (1991). A three-component conceptualization of organizational commitment. Human Resource Management Review, 1, 61-89.

Meyer, J. P., \& Allen, N. J. (1997). Commitment in the workplace: Theory, research, and application. Thousand Oaks, CA: Sage.

Meyer, J. P., Allen, N. J., \& Topolnytsky, L. (1998). Commitment in a changing world of work. Canadian Psychology, 39, 83-93.

Meyer, J. P., Becker, T. E., \& Vandenberghe, C. (2004). Employee commitment and motivation: A conceptual analysis and integrative model. Journal of Applied Psychology, 89, 991-1007. 


\section{6}

Meyer, J. P., \& Herscovitch, L. (2001). Commitment in the workplace: Towards a general model. Human Resource Management Review, 11, 299-326.

Meyer, J. P., Stanley, D. J., Herscovitch, L., \& Topolnytsky, L. (2002). Affective, continuance, and normative commitment to the organization: A meta-analysis of antecedents, correlates, and consequences. Journal of Vocational Behavior, 61, 20-52.

Omoto, A. M., Snyder, M., \& Martino, S. C. (2000). Volunteerism and the life course: Investigating age-related agenda for action. Basic and Applied Social Psychology, 22, $181-197$.

Pearce, J. L. (1993). Volunteers: The organizational behavior of unpaid workers. London: Routledge.

Powell, D. M., \& Meyer, J. P. (2004). Side-bet theory and the three-component model of organizational commitment. Journal of Vocational Behavior, 65, 157-177.

Rousseau, D. M., \& McLean Parks, J. (1993). The contracts of individuals and organizations. In L. L. Cummings \& B. M. Staw (Eds.), Research in organizational behavior (Vol. 15, pp. 1-47). Greenwich, CT: JAI Press.

Tett, R. P., \& Meyer, J. P. (1993). Job satisfaction, organizational commitment, turnover intention, and turnover: Path analysis based on meta-analytic findings. Personnel Psychology, 46, 259-293.

Van Vuuren, M., Veldkamp, B. P., de Jong, M. D. T., \& Seydel, E. R. (in press). Why work? Aligning foci and dimensions of commitment along the axes of the competing values framework. Personnel Review.

Wilson, A., \& Pimm, G. (1996). The tyranny of the volunteer: The care and feeding of voluntary workforces. Management Decision, 34(4), 24-40.

Original manuscript received February 2006 Revised manuscript received September 2006 First published online 19 November 2007 